\title{
Erratum to: Simple model of surface-induced electrolytic dissociation of weak acids in organic solvents
}

\author{
Marek Kosmulski
}

Published online: 25 September 2010

(C) Springer Science+Business Media, LLC 2010

Erratum to: Adsorption (2010) 16:343-349

DOI 10.1007/s10450-010-9239-9

The description of the $x$-axes of Figs. 1-3 was incorrect. Corrected versions of Figs. 1-3 are reproduced on the following page.

The author regrets the error.

The online version of the original article can be found under doi:10.1007/s10450-010-9239-9.

M. Kosmulski (凶)

Center of Excellence for Functional Materials and Graduate

School of Materials Research at Laboratory of Physical

Chemistry, Åbo Akademi University, Åbo, Finland

e-mail: mkosmuls@abo.fi

M. Kosmulski

Department of Electrochemistry, Lublin University

of Technology, Nadbystrzycka 38 A, 20-618 Lublin, Poland 
Fig. 1 The effect of $\mathrm{TiO}_{2}$ on the conductivity of oxalic acid in methanol. The model

parameters are summarized in Table 2

Fig. 2 The effect of $\mathrm{TiO}_{2}$ on the conductivity of oxalic acid in $94 \%$ ethanol. The model parameters are summarized in Table 2

Fig. 3 The effect of $\mathrm{TiO}_{2}$ on the conductivity of phosphoric acid in $94 \%$ ethanol. The model parameters are summarized in Table 2
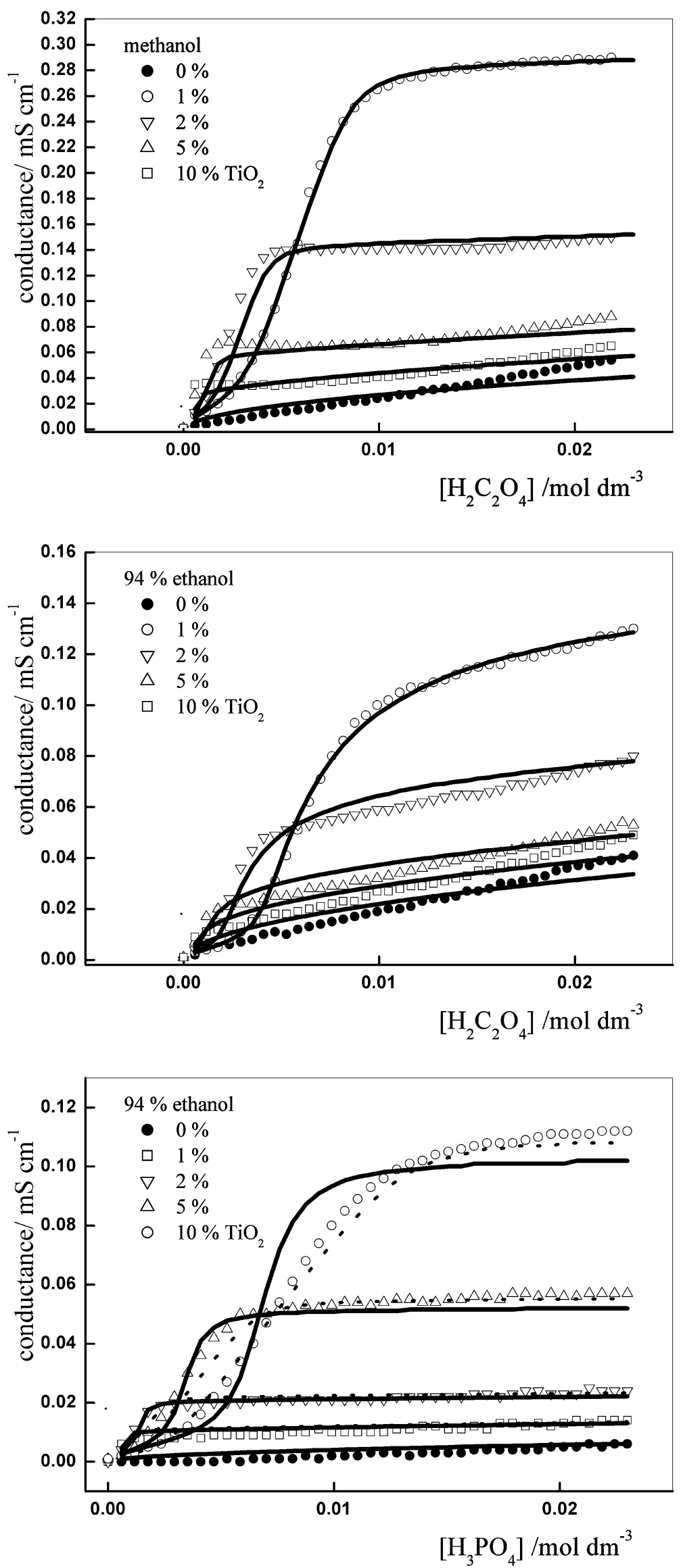